\title{
Climate Change and Pacific Salmon Productivity on the Russian Far East
}

\author{
Alexander V. Bugaev ${ }^{1}$, Oleg B. Tepnin ${ }^{1}$, and Vladimir I. Radchenko ${ }^{2}$ \\ ${ }^{I}$ Kamchatka Fishery and Oceanography Research Institute (KamchatNIRO), 18 Naberezhnaya Street, \\ Petropavlovsk-Kamchatsky 683000, Russia
}

${ }^{2}$ North Pacific Anadromous Fish Commission, Suite 502, 889 West Pender Street, Vancouver, BC V6C 3B2, Canada

Keywords: Pacific salmon, climate variability, climate indices, stock abundance

Climate change impact is a mainstream topic in Pacific salmon stock dynamics research. Numerous studies analyze correlations of some salmon species or stock abundance conditions with one or another climate index. Meanwhile, it is evident that no one factor impacts salmon or their environment separately from other elements of the salmon ecosystem. To understand the importance of the contributions of the main physical elements into changing environmental conditions of salmon ecosystems in the North Pacific Ocean, we tried to evaluate correlations between commercial catches of several salmon species with the most popular climate indices. These indices characterize large-scale meteorological, oceanographic, and cosmo-physical processes defining the Earth's climate. Climate change impacts on Pacific salmon (pink, chum, and sockeye) productivity was assessed based on long-term (1971-2015) fisheries statistics and dynamics of 18 climate indices using stepwise multivariate regression analysis. Three regional stock groups were analyzed: Eastern Kamchatka and Chukotka (BPG), Western Kamchatka and continental coast (NOG), and Sakhalin, Kuriles, Amur River, and Primorye (SOG).

We analyzed salmon catch dynamics in numbers to avoid an influence of fluctuating average salmon body weight. Pink salmon heavily contribute to the total Russian commercial salmon catch, and its predominance is illustrated further when the numbers from catches are reviewed (Fig. 1). Portions of chum and sockeye salmon increased in the last few years, when their commercial catches by Russia regularly reached 100,000 metric tons for chum and 45,000 metric tons for sockeye. If we consider salmon catch dynamics by regional groups and by species, the three selected regional groups contributed comparable portions of the total catch. While the left parts of histograms demonstrate significant interannual variability determined by the interchange of odd- and even-year pink salmon broodlines with different productivity, the right parts show a trend to levelling. The contribution of the NOG and SOG regional stock groups is much more significant for pink and chum salmon. Commercial catch increase is mostly determined by the SOG regional stock group, especially for chum salmon.

Table 1. Correlation matrix of relationships between climate indices used in this study, 1971-2015. Correlation coefficients $(r)$ are shown below mid-line, confidence probability $(p)$-above mid-line.

\begin{tabular}{|c|c|c|c|c|c|c|c|c|c|c|c|c|c|c|c|c|c|c|}
\hline Indices & $\overline{3}$ & $\sum_{i}^{\pi}$ & $z$ & $\stackrel{\circ}{\circ}$ & $\Sigma$ & $\bar{Z}$ & $\Xi$ & ఏ & 之: & 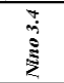 & $\bar{y}$ & 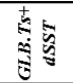 & $\bar{\Delta}$ & $\hat{\nabla}$ & $\bar{\Delta}$ & క్ & కิ & 仓̊ \\
\hline$A L P I$ & 1,000 & 0.000 & 0.181 & 0.009 & 0.000 & 0.094 & 0.769 & 0.000 & 0.260 & 0.439 & 0.000 & 0.295 & 0.807 & 0.608 & 0.623 & 0.394 & 0.261 & 0.858 \\
\hline$P N A$ & 0.566 & 1.000 & 0.019 & 0.012 & 0.000 & 0.233 & 0.883 & 0.002 & 0.018 & 0.285 & 0.003 & 0.015 & 0.457 & 0.162 & 0.302 & 0.247 & 0.091 & 0.165 \\
\hline$N P$ & -0.203 & -0.350 & 1.000 & 0.011 & 0.276 & 0.966 & 0.271 & 0.346 & 0.510 & 0.762 & 0.666 & 0.706 & 0.148 & 0.833 & 0.254 & 0.871 & 0.879 & 0.457 \\
\hline$A O$ & -0.383 & -0.373 & 0.376 & 1.000 & 0.042 & 0.467 & 0.525 & 0.228 & 0.803 & 0.866 & 0.238 & 0.830 & 0.126 & 0.029 & 0.067 & 0.700 & 0.616 & 0.933 \\
\hline$A F I$ & 0.898 & 0.618 & -0.192 & -0.351 & 1.000 & 0.021 & 0.868 & 0.000 & 0.013 & 0.301 & 0.000 & 0.005 & 0.583 & 0.745 & 0.370 & 0.454 & 0.008 & 0.019 \\
\hline$P C I$ & 0.292 & 0.210 & 0.008 & 0.129 & 0.395 & 1.000 & 0.672 & 0.077 & 0.000 & 0.103 & 0.074 & 0.000 & 0.231 & 0.991 & 0.291 & 0.257 & 0.000 & 0.000 \\
\hline$W P$ & -0.045 & -0.023 & 0.168 & 0.097 & -0.030 & -0.075 & 1.000 & 0.754 & 0.132 & 0.370 & 0.576 & 0.112 & 0.399 & 0.387 & 0.634 & 0.192 & 0.117 & 0.102 \\
\hline$P D O$ & 0.530 & 0.459 & -0.144 & -0.183 & 0.659 & 0.307 & -0.048 & 1.000 & 0.740 & 0.000 & 0.004 & 0.748 & 0.831 & 0.281 & 0.884 & 0.000 & 0.926 & 0.721 \\
\hline N.HEMI+dSST & 0.172 & 0.350 & 0.101 & 0.038 & 0.420 & 0.808 & -0.228 & 0.051 & 1.000 & 0.139 & 0.357 & 0.000 & 0.996 & 0.002 & 0.600 & 0.998 & 0.000 & 0.000 \\
\hline Nino 3.4 & 0.118 & 0.163 & -0.047 & 0.026 & 0.183 & 0.284 & 0.137 & 0.558 & 0.224 & 1.000 & 0.100 & 0.084 & 0.789 & 0.681 & 0.384 & 0.000 & 0.854 & 0.512 \\
\hline$B S I$ & 0.603 & 0.470 & 0.071 & -0.194 & 0.678 & 0.343 & 0.092 & 0.454 & 0.152 & 0.267 & 1.000 & 0.412 & 0.864 & 0.791 & 0.704 & 0.103 & 0.298 & 0.911 \\
\hline$G L B . T S+d S S T$ & 0.160 & 0.359 & 0.058 & -0.033 & 0.466 & 0.766 & -0.240 & 0.049 & 0.983 & 0.260 & 0.135 & 1.000 & 0.914 & 0.001 & 0.542 & 0.895 & 0.000 & 0.000 \\
\hline SSF & -0.037 & -0.114 & -0.219 & 0.232 & -0.098 & 0.211 & 0.129 & -0.033 & -0.001 & 0.041 & -0.028 & -0.017 & 1.000 & 0.002 & 0.000 & 0.470 & 0.910 & 0.440 \\
\hline$A p$ & 0.079 & -0.212 & 0.032 & 0.326 & -0.058 & -0.002 & 0.132 & 0.164 & -0.446 & 0.063 & 0.044 & -0.491 & 0.450 & 1.000 & 0.000 & 0.133 & 0.016 & 0.001 \\
\hline SSI & -0.075 & -0.157 & -0.174 & 0.275 & -0.159 & 0.186 & 0.073 & 0.022 & -0.080 & 0.133 & -0.063 & -0.093 & 0.942 & 0.524 & 1.000 & 0.130 & 0.442 & 0.287 \\
\hline$O L R$ & -0.140 & -0.190 & 0.027 & -0.064 & -0.145 & -0.218 & -0.213 & -0.643 & -0.001 & -0.934 & -0.280 & -0.022 & -0.119 & -0.245 & -0.247 & 1.000 & 0.204 & 0.388 \\
\hline LOD & -0.173 & -0.258 & 0.024 & 0.078 & -0.449 & -0.804 & 0.240 & 0.014 & -0.827 & -0.029 & -0.173 & -0.823 & 0.018 & 0.360 & 0.119 & -0.211 & 1.000 & 0.000 \\
\hline $\mathrm{OHC}-700$ & 0.035 & 0.211 & 0.103 & -0.010 & 0.368 & 0.806 & -0.284 & -0.052 & 0.912 & 0.113 & 0.013 & 0.921 & -0.109 & -0.533 & -0.178 & 0.132 & -0.804 & 1.000 \\
\hline
\end{tabular}

Remarks: Significant correlation coefficients $(p<0.05-0.001)$ are highlighted in bold. Number of data values available for each index, $N=45$ for ALPI, PNA, NP, AO, WP, PDO, N.HEMI+dSST, Nino 3.4, GLB.Ts+dSST, SSF, Ap, SSI, and OHC-700 indices, $N=44$ for LOD, $N=39$ for BSI and OLR, and $N=34$ for AFI and PCI.

A set of eighteen climate indices with different dynamics may also be conditionally divided by three groups. The meteorological indices include the Aleutian Low Pressure Index (ALPI), the North Pacific Index (NPI), the Atmospheric Forcing Index (AFI), the Pacific-North American Oscillation (PNA), the Arctic Oscillation (AO), and the West Pacific Teleconnection Index (WP). Oceanological indices examined in this study include the Pacific 
Decadal Oscillation (PDO), GLOBAL Land-Ocean Temperature Index (LOTI), the Bering Sea Ice Cover Index (BSI), the Northern Hemisphere Land and Sea Surface Temperature Anomalies (N.HEMI+dSST), Nino 3.4 Index, and the Global Ocean Heat Content for the upper 700-meter layer (OHC-700). The three indices that are calculated using sea surface temperature (SST), N.HEMI+dSST, LOTI, and OHC-700, have similar positive trends, which reflect growing temperature of the ocean surface layer, as well as progressive heat accumulation (Levitus et al. 2005).

The third group consists of cosmo-physical indices including the Solar Flux (SFI) and the Solar Spot (SSI) Indices, the Geomagnetic Disturbance Index (Ap), Length of the Day (LOD), Outgoing Longwave Radiation Index (OLR), and the Winter Pacific Circulation Index (PCI). The last index may be included into the meteorological group. It is calculated as the sum of the negative anomalies of the northwestern transport of air masses. The higher index means the stronger southwest inflow to the coast of North America and increases in heat influx. This relates it to the SST-related oceanological indices with the well-expressed positive trend since 1975, which were mentioned earlier. Index values were averaged using a moving average technique over a two-year period for comparisons with pink salmon catch dynamics, and over a four-year period for sockeye and chum salmon.

Results of correlation analysis of the relationship between climate indices based on 1971-2015 data showed that about $30 \%$ of correlations occurred were significant (Table 1). The highest positive correlation coefficients are observed between the SST-related oceanological indices, in pairs of them and with the WP index, between the SFI and SSI, and also between the AFI and ALPI. The strongest negative correlations are observed between the LOD and the SST-related oceanological indices, as well as WP, and between the OLR and the Nino 3.4 indices. The latter is rather understandable since the higher Nino 3.4 Index characterizes a situation when the cold Peruvian Current is well developed and transports relatively cold waters to the equatorial region, while the OLR characterizes the heating of surface waters and the intensity of evaporation near the equator.

Table 2. Pearson's correlation coefficients $(r)$ and confidence probability $(p)$ between salmon commercial catches of different regional groups (nearshore and in-river fisheries on the Russian Far East, 1,000 fish) and annual values of eighteen selected climate indices, 1971-2015.

\begin{tabular}{|c|c|c|c|c|c|c|c|c|c|c|c|c|c|c|c|c|}
\hline \multirow{3}{*}{ Indices } & \multicolumn{6}{|c|}{ Pink salmon } & \multicolumn{6}{|c|}{ Chum salmon } & \multicolumn{4}{|c|}{ Sockeye salmon } \\
\hline & \multicolumn{2}{|c|}{ BPG } & \multicolumn{2}{|c|}{ NOG } & \multicolumn{2}{|c|}{ SOG } & \multicolumn{2}{|c|}{ BPG } & \multicolumn{2}{|c|}{ NOG } & \multicolumn{2}{|c|}{ SOG } & \multicolumn{2}{|c|}{ BPG } & \multicolumn{2}{|c|}{ NOG } \\
\hline & $r$ & $p$ & $r$ & $p$ & $r$ & $p$ & $r$ & $p$ & $r$ & $p$ & $r$ & $p$ & $r$ & $p$ & $r$ & $p$ \\
\hline ALPI & 0.07 & 0.698 & 0.26 & 0.138 & -0.03 & 0.875 & 0.68 & 0.000 & 0.28 & 0.096 & 0.24 & 0.148 & 0.39 & 0.016 & 0.22 & 0.196 \\
\hline AFI & 0.05 & 0.771 & 0.20 & 0.239 & 0.06 & 0.718 & 0.68 & 0.000 & 0.39 & 0.017 & 0.45 & 0.005 & 0.38 & 0.021 & 0.41 & 0.011 \\
\hline PCI & 0.18 & 0.289 & 0.23 & 0.193 & 0.46 & 0.005 & 0.25 & 0.128 & 0.83 & 0.000 & 0.52 & 0.001 & 0.64 & 0.000 & 0.88 & 0.000 \\
\hline PNA & 0.13 & 0.469 & 0.32 & 0.058 & 0.06 & 0.749 & 0.67 & 0.000 & 0.46 & 0.004 & 0.43 & 0.008 & 0.52 & 0.001 & 0.37 & 0.023 \\
\hline NP & 0.07 & 0.704 & -0.23 & 0.185 & 0.03 & 0.855 & -0.22 & 0.195 & 0.23 & 0.176 & -0.04 & 0.813 & -0.02 & 0.904 & 0.17 & 0.325 \\
\hline AO & 0.12 & 0.487 & -0.06 & 0.741 & 0.09 & 0.597 & -0.12 & 0.472 & 0.20 & 0.243 & 0.01 & 0.942 & -0.02 & 0.910 & 0.39 & 0.016 \\
\hline WP & 0.07 & 0.678 & 0.07 & 0.684 & 0.03 & 0.876 & 0.11 & 0.508 & -0.18 & 0.294 & 0.08 & 0.648 & -0.04 & 0.792 & -0.11 & 0.530 \\
\hline PDO & -0.20 & 0.215 & -0.27 & 0.090 & -0.49 & 0.001 & -0.06 & 0.726 & -0.26 & 0.093 & -0.41 & 0.007 & -0.38 & 0.012 & -0.33 & 0.034 \\
\hline N.HEMI+dSST & 0.34 & 0.034 & 0.31 & 0.050 & 0.61 & 0.000 & 0.55 & 0.000 & 0.81 & 0.000 & 0.68 & 0.000 & 0.76 & 0.000 & 0.87 & 0.000 \\
\hline Nino 3.4 & -0.05 & 0.758 & -0.04 & 0.800 & -0.06 & 0.707 & -0.02 & 0.899 & 0.17 & 0.296 & -0.07 & 0.659 & 0.00 & 0.998 & 0.09 & 0.581 \\
\hline GLB.Ts+dSST & 0.33 & 0.036 & 0.31 & 0.053 & 0.62 & 0.000 & 0.57 & 0.000 & 0.82 & 0.000 & 0.72 & 0.000 & 0.78 & 0.000 & 0.88 & 0.000 \\
\hline BSI & -0.10 & 0.523 & -0.10 & 0.522 & -0.28 & 0.081 & -0.12 & 0.442 & -0.25 & 0.113 & -0.36 & 0.018 & -0.29 & 0.065 & -0.13 & 0.429 \\
\hline OHC-700 & 0.35 & 0.037 & 0.33 & 0.031 & 0.66 & 0.000 & 0.57 & 0.000 & 0.87 & 0.000 & 0.77 & 0.000 & 0.83 & 0.000 & 0.66 & 0.000 \\
\hline SSF & -0.11 & 0.503 & -0.07 & 0.649 & -0.26 & 0.100 & -0.09 & 0.571 & -0.35 & 0.026 & -0.24 & 0.126 & -0.32 & 0.043 & -0.13 & 0.420 \\
\hline Ap & -0.32 & 0.043 & -0.24 & 0.138 & -0.54 & 0.000 & -0.52 & 0.000 & -0.76 & 0.000 & -0.75 & 0.000 & -0.81 & 0.000 & -0.65 & 0.000 \\
\hline SSI & -0.15 & 0.347 & -0.10 & 0.546 & -0.30 & 0.058 & -0.15 & 0.360 & -0.34 & 0.028 & -0.29 & 0.068 & -0.35 & 0.027 & -0.18 & 0.253 \\
\hline OLR & 0.20 & 0.202 & 0.14 & 0.389 & 0.33 & 0.034 & 0.22 & 0.160 & 0.16 & 0.325 & 0.32 & 0.040 & 0.33 & 0.034 & 0.18 & 0.260 \\
\hline LOD & -0.17 & 0.278 & -0.23 & 0.154 & -0.51 & 0.001 & -0.47 & 0.002 & -0.60 & 0.000 & -0.50 & 0.001 & -0.53 & 0.000 & -0.77 & 0.000 \\
\hline
\end{tabular}

Remark: Casewise deletion of missing data is applied.

The correlation analysis was a primary stage in determining the relationships between the productivity of Pacific salmon and climate variability. Index selection was based on correlation coefficients having a weak (from 0.3 to 0.5 ), moderate (from 0.5 to 0.75 ) or a higher level of significance. The minimum number of significant correlations are observed between the climate indices and commercial catches of pink salmon (Table 2).

Correlations with a moderate level of significance are calculated for the SOG only. Positive correlations are observed between pink salmon catch and the SST-related oceanological indices, while negative ones are observed with the Ap and LOD indices. For chum and sockeye salmon, moderate and strong "index-catch" relationships are noted in most cases. For all regional groups and even for all salmon species under consideration, relationships with climate indices have the same negative or positive sign. Based on the results of correlation analysis, it may be concluded that pink salmon is least affected by climate change impacts while chum and sockeye salmon are affected 
almost to the same degree. This may be due to the shorter duration of marine phase for pink and similar duration of the marine phase for two other salmon species.

Table 3. Results of multivariate regression modelling of pink salmon commercial catches of different regional groups (nearshore and in-river fisheries on the Russian Far East, 1,000 fish) and annual values of ten selected climate indices, 1971-2015.

\begin{tabular}{|c|c|c|c|c|c|c|c|c|c|c|c|c|c|}
\hline \multirow{2}{*}{$\begin{array}{l}\text { Regional } \\
\text { group of } \\
\text { stocks }\end{array}$} & \multicolumn{6}{|c|}{ Multiple regression result } & \multicolumn{7}{|c|}{ Regression summary for dependent variable } \\
\hline & $R$ & $R^{2}$ & $S E$ & $F$ & $d f$ & $p$ & Predictor & Beta & $S E(B e t a)$ & $B$ & $S E(B)$ & $t$ & $p$ \\
\hline \multirow[t]{3}{*}{ BPG } & 0.38 & 0.14 & 30394.0 & 3.50 & 2.42 & $<0.05$ & $b_{0}$ (intercept) & & & 39130.9 & 21663.3 & 1.81 & 0.078 \\
\hline & & & & & & & $b_{1}(\mathrm{~N} . \mathrm{HEMI}+\mathrm{dSST})$ & 0.24 & 0.17 & 235.1 & 162.0 & 1.45 & 0.154 \\
\hline & & & & & & & $b_{2}(\mathrm{Ap})$ & -0.19 & 0.17 & -1534.9 & 1304.6 & -1.18 & 0.246 \\
\hline \multirow[t]{4}{*}{ SOG } & 0.75 & 0.56 & 25924.1 & 17.54 & 3.41 & $<0.001$ & $b_{0}$ (intercept) & & & 45581.7 & 8405.3 & 5.42 & $<0.001$ \\
\hline & & & & & & & $b_{1}(\mathrm{~N} . \mathrm{HEMI}+\mathrm{dSST})$ & 0.60 & 0.10 & 689.6 & 119.8 & 5.76 & $<0.001$ \\
\hline & & & & & & & $b_{2}(\mathrm{PDO})$ & -0.35 & 0.10 & -17413.1 & 5207.6 & -3.34 & $<0.01$ \\
\hline & & & & & & & $b_{3}(\mathrm{SSI})$ & -0.22 & 0.10 & -125.5 & 60.6 & -2.07 & $<0.05$ \\
\hline \multirow[t]{2}{*}{ NOG } & 0.36 & 0.13 & 22934.4 & 6.22 & 1.43 & $<0.05$ & $b_{0}($ intercept $)$ & & & 10486.2 & 5314.9 & 1.97 & 0.055 \\
\hline & & & & & & & $b_{1}(\mathrm{~N} . \mathrm{HEMI}+\mathrm{dSST})$ & 0.36 & 0.14 & 263.1 & 105.5 & 2.49 & $<0.05$ \\
\hline \multirow[t]{4}{*}{ Far East } & 0.74 & 0.55 & 46000.1 & 16.72 & 3.41 & $<0.001$ & $b_{0}$ (intercept) & & & 79713.0 & 14914.6 & 5.34 & $<0.001$ \\
\hline & & & & & & & $b_{1}(\mathrm{~N} . \mathrm{HEMI}+\mathrm{dSST})$ & 0.63 & 0.11 & 1266.2 & 212.5 & 5.96 & $<0.001$ \\
\hline & & & & & & & $b_{2}(\mathrm{PDO})$ & -0.29 & 0.10 & -25223.9 & 9240.4 & -2.73 & $<0.01$ \\
\hline & & & & & & & $b_{3}(\mathrm{SSI})$ & -0.20 & 0.11 & -203.8 & 107.5 & -1.90 & 0.065 \\
\hline
\end{tabular}

Remarks: Statistical parameters: $R$ —coefficient of multivariate regression, $R^{2}$ —determination coefficient, $S E$ - standard error, $F$ - F-criterion, $d f$ - degrees of freedom for each regression, $p$ - confidence probability, $b_{0}$ - constant term or the axis $y$ intercept, $b_{1}, b_{2}$-regression coefficients, Beta $u B$-standardized and non-standardized regression coefficients ("weights"). $N=45$.

To select climate indices that are more relevant for future use, we reduced the number of variables based on factor analysis. A set of ten climate indices with dynamics in a good agreement with fluctuations of Pacific salmon catches were selected by correlation analysis: ALPI, PNA, WP, PDO, NP, AO, N.HEMI+dSST, Ap, SSI, and LOD, which were used for the multivariate regression analysis. Results of multivariate regression modelling of pink salmon catches with mean annual values of climate indices are presented in Table 3 . The lowest values of regression coefficients are received for pink salmon, which imply a weak correlation between productivity: $\mathrm{R}=0.38$ for BPG, 0.36 for NOG, and 0.75 for SOG. Significant relationships exist with four climate indices,

N.HEMI+dSST, PDO, Ap, and SSI, and the strongest one, between catches in SOG and the N.HEMI+dSST index. For all regional groups, N.HEMI+dSST reflects the strongest effect of positive near-surface air temperature and SST anomalies on pink salmon productivity: beta coefficient varies from 0.24 to 0.60 . In SOG, PDO reflects the negative effect of negative winter SST anomalies in central and western North Pacific: beta coefficient $=-0.35$.

Moderate to high values of regression coefficients are received for chum salmon: $\mathrm{R}=0.71$ for $\mathrm{BPG}, 0.93$ for NOG, and 0.86 for SOG, and sockeye: $0.91-0.92$ for BPG and NOG, respectively (Tables 4-5). The strongest correlations for two of three regional chum stocks groups and for one sockeye group are observed with the Ap index that reflects a negative effect of positive geomagnetic disturbance anomalies: beta coefficients ranged -0.37 to -0.25 for chum and -0.14 to -0.42 for sockeye. Ap is a measure of the general level of geomagnetic activity over the globe for a given day. It is derived from measurements made at eleven stations worldwide of the variation of the geomagnetic field due to currents flowing in the earth's ionosphere and, to a lesser extent, in the earth's magnetosphere. In its physical sense, the Ap is an overall measure of solar wind-magnetosphere interactions and is usually used in correlation studies of interplanetary and solar phenomena. The N.HEMI+dSST indicator reflects the strongest effect of positive temperature anomalies: beta coefficients ranged $0.65-0.91$ for chum and $0.61-0.85$ for sockeye. The significance of indices for the BPG and NOG groups of chum and sockeye salmon is the opposite. Likely, there is a connection with Saito and Miyakoshi's (2018) observations, who emphasized the significance of SST dynamics for chum salmon survival in the Sea of Okhotsk. Proceeding from results of multivariate regression modelling, it may be concluded that the thermal conditions of upper water layer and dynamics of solar activity are the major drivers of these three species of Pacific salmon productivities in the North Pacific Ocean (Radchenko et al. 2007; Bugaev et al. 2016). 
Table 4. Results of multivariate regression modelling of chum salmon commercial catches of different regional groups (nearshore and in-river fisheries on the Russian Far East, 1,000 fish) and annual values of ten selected climate indices, 1971-2015.

\begin{tabular}{|c|c|c|c|c|c|c|c|c|c|c|c|c|c|}
\hline \multirow{2}{*}{$\begin{array}{c}\text { Regional } \\
\text { group of } \\
\text { stocks }\end{array}$} & \multicolumn{6}{|c|}{ Multiple regression result } & \multicolumn{7}{|c|}{ Regression summary for dependent variable } \\
\hline & $R$ & $R^{2}$ & $S E$ & $F$ & $d f$ & $p$ & Predictor & Beta & $S E($ Beta $)$ & $B$ & $S E(B)$ & $t$ & $p$ \\
\hline \multirow[t]{7}{*}{ BPG } & 0.71 & 0.51 & 1228.3 & 6.53 & 6.38 & $<0.001$ & $b_{0}$ (intercept) & & & 7712.5 & 1887.7 & 4.09 & $<0.001$ \\
\hline & & & & & & & $b_{1}(\mathrm{~N} . \mathrm{HEMI}+\mathrm{dSST})$ & -0.13 & 0.23 & -6.9 & 11.9 & -0.58 & 0.564 \\
\hline & & & & & & & $b_{2}(\mathrm{Ap})$ & -0.94 & 0.30 & -434.0 & 136.7 & -3.17 & $<0.01$ \\
\hline & & & & & & & $b_{3}(\mathrm{ALPI})$ & 0.59 & 0.19 & 819.6 & 255.4 & 3.21 & $<0.01$ \\
\hline & & & & & & & $b_{4}(\mathrm{AO})$ & 0.43 & 0.20 & 2983.0 & 1378.7 & 2.16 & $<0.05$ \\
\hline & & & & & & & $b_{5}(\mathrm{WP})$ & -0.24 & 0.13 & -1820.9 & 986.4 & -1.85 & 0.073 \\
\hline & & & & & & & $b_{6}(\mathrm{SSI})$ & 0.28 & 0.16 & 8.3 & 4.8 & 1.72 & 0.093 \\
\hline \multirow[t]{6}{*}{ SOG } & 0.86 & 0.74 & 3736.0 & 22.18 & 5.39 & $<0.001$ & $b_{0}$ (intercept) & & & 45057.6 & 16500.7 & 2.73 & $<0.01$ \\
\hline & & & & & & & $b_{1}(\mathrm{Ap})$ & -0.90 & 0.11 & -1767.0 & 221.4 & -7.98 & $<0.001$ \\
\hline & & & & & & & $b_{2}(\mathrm{WP})$ & -0.33 & 0.09 & -10831.6 & 2820.1 & -3.84 & $<0.001$ \\
\hline & & & & & & & $b_{3}(\mathrm{AO})$ & 0.34 & 0.11 & 9917.1 & 3164.4 & 3.13 & $<0.001$ \\
\hline & & & & & & & $b_{4}(\mathrm{SSI})$ & 0.22 & 0.11 & 27.2 & 13.7 & 1.99 & 0.054 \\
\hline & & & & & & & $b_{5}(\mathrm{NP})$ & -0.12 & 0.11 & -1376.5 & 1212.0 & -1.14 & 0.263 \\
\hline \multirow[t]{8}{*}{ NOG } & 0.93 & 0.86 & 1230.9 & 32.79 & 7.37 & $<0.001$ & $b_{0}$ (intercept) & & & 4328.0 & 2376.5 & 1.82 & 0.077 \\
\hline & & & & & & & $b_{1}(\mathrm{~N} \cdot \mathrm{HEMI}+\mathrm{dSST})$ & 0.76 & 0.18 & 73.2 & 17.3 & 4.23 & $<0.001$ \\
\hline & & & & & & & $b_{2}(\mathrm{Ap})$ & -0.44 & 0.12 & -377.3 & 104.9 & -3.60 & $<0.001$ \\
\hline & & & & & & & $b_{3}(\mathrm{WP})$ & -0.21 & 0.07 & -2942.5 & 1003.0 & -2.93 & $<0.001$ \\
\hline & & & & & & & $b_{4}(\mathrm{LOD})$ & 0.26 & 0.16 & 926.7 & 586.2 & 1.58 & 0.122 \\
\hline & & & & & & & $b_{5}(\mathrm{AO})$ & 0.10 & 0.10 & 1310.3 & 1344.4 & 0.97 & 0.336 \\
\hline & & & & & & & $b_{6}(\mathrm{PDO})$ & 0.24 & 0.12 & 1215.0 & 583.3 & 2.08 & $<0.05$ \\
\hline & & & & & & & $b_{7}(\mathrm{ALPI})$ & -0.19 & 0.14 & -487.2 & 368.8 & -1.32 & 0.195 \\
\hline
\end{tabular}

See remarks in Table 3.

Table 5. Results of multivariate regression modelling of sockeye salmon commercial catches of different regional groups (nearshore and in-river fisheries on the Russian Far East, 1,000 fish) and annual values of ten selected climate indices, 1971-2015.

\begin{tabular}{|c|c|c|c|c|c|c|c|c|c|c|c|c|c|}
\hline \multirow{2}{*}{$\begin{array}{l}\text { Regional } \\
\text { group of } \\
\text { stocks }\end{array}$} & \multicolumn{6}{|c|}{ Multiple regression result } & \multicolumn{7}{|c|}{ Regression summary for dependent variable } \\
\hline & $R$ & $R^{2}$ & $S E$ & $F$ & $d f$ & $p$ & Predictor & Beta & $S E($ Beta) & $B$ & $S E(B)$ & $t$ & $p$ \\
\hline \multirow[t]{5}{*}{ BPG } & 0.91 & 0.82 & 773.2 & 45.67 & 4.40 & $<0.001$ & $b_{0}$ (intercept) & & & 1510.0 & 1175.8 & 1.28 & 0.206 \\
\hline & & & & & & & $b_{1}(\mathrm{Ap})$ & -0.42 & 0.08 & -207.8 & 41.1 & -5.05 & $<0.001$ \\
\hline & & & & & & & $b_{2}(\mathrm{~N} . \mathrm{HEMI}+\mathrm{dSST})$ & 0.85 & 0.17 & 46.7 & 9.6 & 4.87 & $<0.001$ \\
\hline & & & & & & & $b_{3}(\mathrm{WP})$ & -0.21 & 0.07 & -1710.2 & 603.1 & -2.84 & $<0.01$ \\
\hline & & & & & & & $b_{4}(\mathrm{LOD})$ & 0.44 & 0.16 & 911.7 & 329.5 & 2.77 & $<0.01$ \\
\hline \multirow[t]{8}{*}{ NOG } & 0.92 & 0.85 & 1458.9 & 30.93 & 7.37 & $<0.001$ & $b_{0}$ (intercept) & & & 10393.0 & 3160.2 & 3.29 & $<0.01$ \\
\hline & & & & & & & $b_{1}(\mathrm{~N} . \mathrm{HEMI}+\mathrm{dSST})$ & 0.27 & 0.21 & 29.6 & 23.0 & 1.29 & 0.205 \\
\hline & & & & & & & $b_{2}(\mathrm{ALPI})$ & -0.03 & 0.10 & -85.0 & 307.4 & -0.28 & 0.784 \\
\hline & & & & & & & $b_{3}(\mathrm{WP})$ & -0.17 & 0.07 & -2796.7 & 1174.8 & -2.38 & $<0.05$ \\
\hline & & & & & & & $b_{4}(\mathrm{LOD})$ & -0.32 & 0.17 & -1339.7 & 691.1 & -1.94 & 0.060 \\
\hline & & & & & & & $b_{5}(\mathrm{Ap})$ & -0.46 & 0.17 & -454.5 & 166.4 & -2.73 & $<0.05$ \\
\hline & & & & & & & $b_{6}(\mathrm{AO})$ & 0.25 & 0.11 & 3728.3 & 1649.9 & 2.26 & $<0.05$ \\
\hline & & & & & & & $b_{7}(\mathrm{SSI})$ & 0.16 & 0.09 & 10.3 & 5.9 & 1.76 & 0.087 \\
\hline \multirow[t]{7}{*}{ Far East } & 0.93 & 0.86 & 2009.8 & 40.21 & 6.38 & $<0.001$ & $b_{0}$ (intercept) & & & 10285.8 & 2383.3 & 4.32 & $<0.001$ \\
\hline & & & & & & & $b_{1}(\mathrm{~N} . \mathrm{HEMI}+\mathrm{dSST})$ & 0.59 & 0.12 & 94.6 & 19.5 & 4.85 & $<0.001$ \\
\hline & & & & & & & $b_{2}(\mathrm{Ap})$ & -0.44 & 0.12 & -634.6 & 166.6 & -3.81 & $<0.001$ \\
\hline & & & & & & & $b_{3}(\mathrm{PNA})$ & -0.07 & 0.09 & -2087.7 & 2868.5 & -0.73 & 0.471 \\
\hline & & & & & & & $b_{4}(\mathrm{WP})$ & -0.17 & 0.07 & -4144.2 & 1718.6 & -2.41 & $<0.05$ \\
\hline & & & & & & & $b_{5}(\mathrm{AO})$ & 0.15 & 0.09 & 3151.0 & 1908.1 & 1.65 & 0.107 \\
\hline & & & & & & & $b_{6}(\mathrm{SSI})$ & 0.11 & 0.08 & 9.6 & 7.5 & 1.27 & 0.211 \\
\hline
\end{tabular}

See remarks in Table 3. 

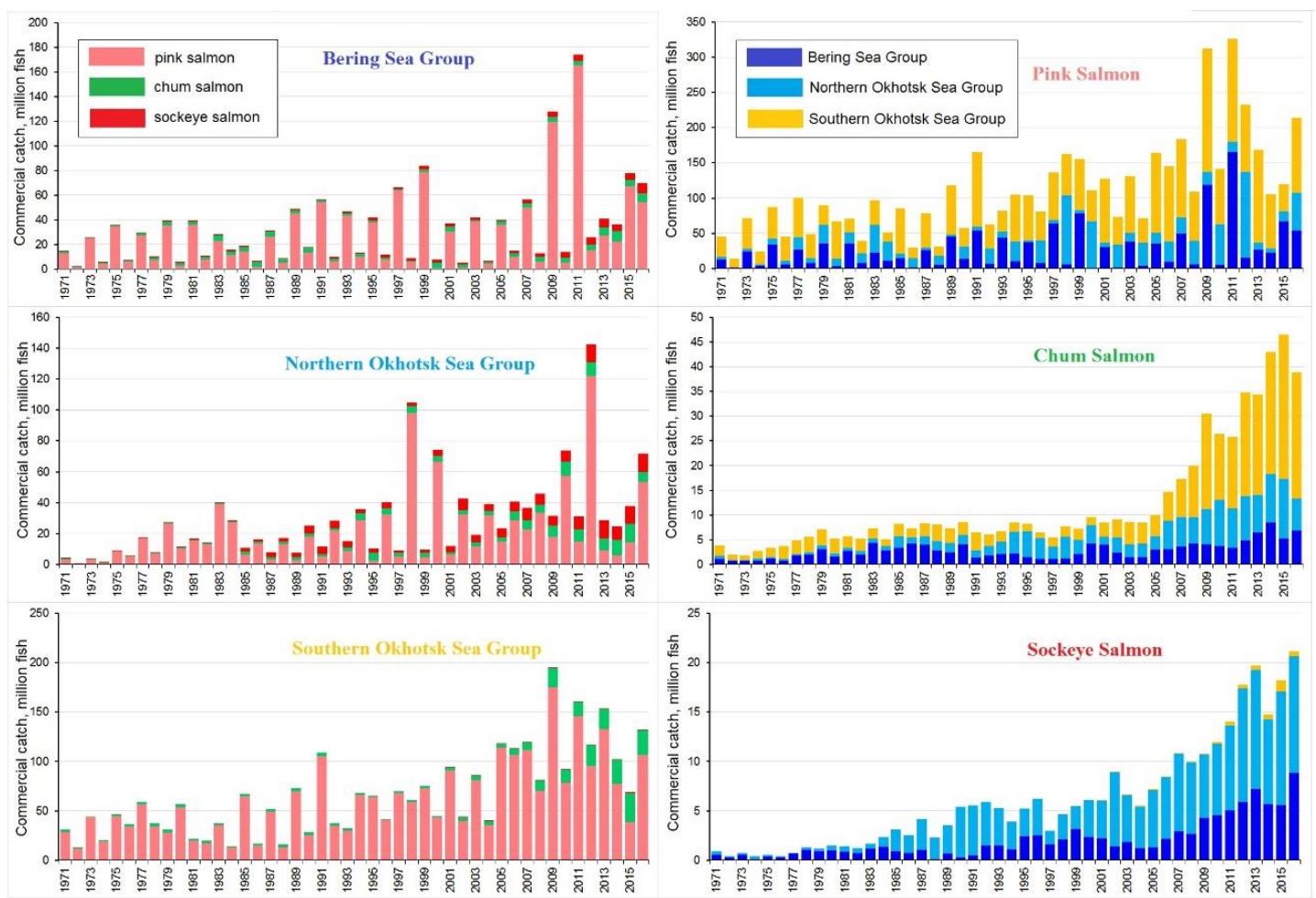

Fig. 1. Commercial catch of Pacific salmon (nearshore and in-river fisheries) in the Russian Far East by species and selected regional stock groups, 1971-2016.
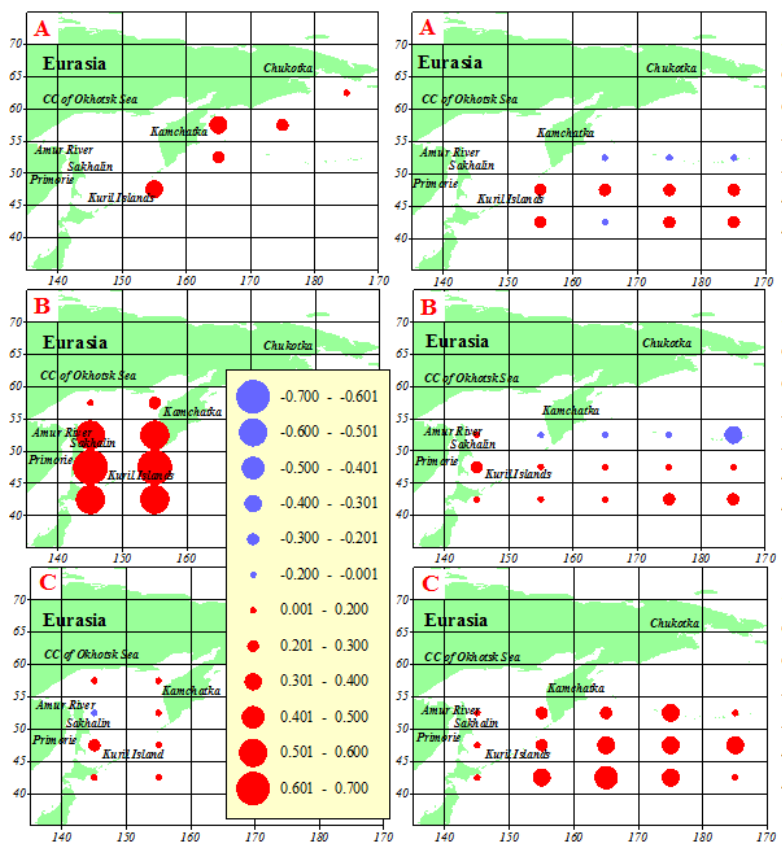

Fig. 2. Distribution of the Pearson's correlation coefficient values between pink salmon commercial catches $(1,000$ fish) by regional stock groups and SST anomalies in salmon first marine autumn (left panels) and winter (right panels). Regional stock groups: A-BPG, B-SOG, and $\mathrm{C}-\mathrm{NOG}$.

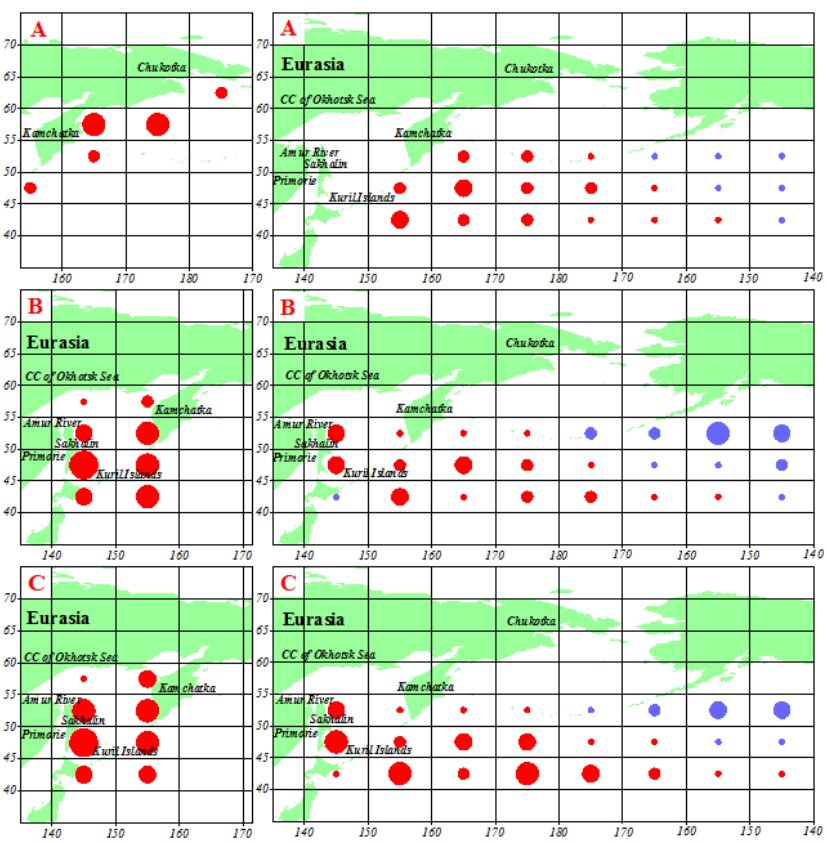

Fig. 3. Distribution of the Pearson's correlation coefficient values between chum salmon commercial catches $(1,000$ fish) by regional stock groups and SST anomalies in salmon first marine autumn (left panels) and winter (right panels). Regional stock groups: A-BPG, B-SOG, and C-NOG. Circles size - as on Fig. 2. 
After we determined the main drivers of Pacific salmon productivity, we tried to explore their influence in the geographical aspect. To analyze the interannual variability of the temperature conditions in the areas of autumn and winter salmon feeding migrations, a conditional division of the Northern Pacific into 39 cartographic trapezoids was carried out with a longitude step of $10^{\circ}$ and a latitude step of $5^{\circ}$. We built distribution maps of Pearson correlation coefficient $(r)$ for the statistical relationship between commercial salmon catches by regional groups and SST anomalies during the autumnal outmigration (September-November) and wintering (December-February) of salmon juveniles in their first year at sea. Satellite monitoring data from 1982-2015 was used. Catches in numbers were calculated in view of the age of maturity and spawning return ( 0.1 for pink, $0.3-0.4$ for chum, and n.2-n.3 for sockeye). Satellite SST data was used from those regions only, where autumn and winter migrations of Pacific salmon from the Far Eastern stocks migrate during the first year of their marine residence.

During the oceanward migration of juvenile pink salmon in September-November, the highest positive correlation between the SST anomalies and catch value was observed for the SOG group of stocks. These positive correlations are observed in the central and southern part of the Sea of Okhotsk, as well as in the Kurile Islands' waters in the Pacific Ocean (Fig. 2). The Pearson correlation coefficients in these regions range from 0.52 to 0.70 . While weak positive correlations are noted for the BPG pink salmon throughout their migration areas, no significant correlations are found for the NOG since juvenile pink salmon originated from this region leave the Sea of Okhotsk earlier and are smaller than pink salmon that originated from the southern areas. Conversely, moderate correlations for the NOG are observed in the northwestern Pacific in December-February. The maximum coefficients reach a level of $r=0.3-0.4$. No significant correlations were found for two other regional groups of pink salmon stocks. This explains why the strength of the relationship between the total Russian pink salmon catch and heat budget of the upper ocean layer, which was revealed in mid-2000s, weakens with a growth of the Bering Sea and Western Kamchatka contributions into the total pink salmon harvest in Russia.

An anomalously warm temperature regime of the waters during the autumn migration of juvenile chum salmon promotes productivity of stocks in all three groups during their migrations in the central and southern Okhotsk Sea, the south-western Bering Sea, and the Pacific waters along the Kuril Islands and Kamchatka Peninsula (Fig. 3). The maximum correlation coefficients vary in a range of $r=0.4-0.6$. In winter, the strength of the relationship weakens with an expansion of the chum juveniles' distribution along the Subarctic Current front. It is remarkable that the distribution of positive and negative correlation coefficients reflects a typical position of two water domains with opposite SST anomalies on the well-known illustration of the PDO model (Mantua et al. 1997).

Table 5. Results of multivariate regression modelling of sockeye salmon commercial catches of different regional groups (nearshore and in-river fisheries on the Russian Far East, 1,000 fish) and annual values of ten selected climate indices, 1971-2015.

\begin{tabular}{|c|c|c|c|c|c|c|c|c|c|c|c|c|c|}
\hline \multirow{2}{*}{$\begin{array}{c}\text { Regional } \\
\text { group of } \\
\text { stocks }\end{array}$} & \multicolumn{6}{|c|}{ Multiple regression result } & \multicolumn{7}{|c|}{ Regression summary for dependent variable } \\
\hline & $R$ & $R^{2}$ & $S E$ & $F$ & $d f$ & $p$ & Predictor & Beta & $S E(B e t a)$ & $B$ & $S E(B)$ & $t$ & $p$ \\
\hline \multirow[t]{5}{*}{ BPG } & 0.91 & 0.82 & 773.2 & 45.67 & 4.40 & $<0.001$ & $b_{0}$ (intercept) & & & 1510.0 & 1175.8 & 1.28 & 0.206 \\
\hline & & & & & & & $b_{1}(\mathrm{Ap})$ & -0.42 & 0.08 & -207.8 & 41.1 & -5.05 & $<0.001$ \\
\hline & & & & & & & $b_{2}(\mathrm{~N} . \mathrm{HEMI}+\mathrm{dSST})$ & 0.85 & 0.17 & 46.7 & 9.6 & 4.87 & $<0.001$ \\
\hline & & & & & & & $b_{3}(\mathrm{WP})$ & -0.21 & 0.07 & -1710.2 & 603.1 & -2.84 & $<0.01$ \\
\hline & & & & & & & $b_{4}(\mathrm{LOD})$ & 0.44 & 0.16 & 911.7 & 329.5 & 2.77 & $<0.01$ \\
\hline \multirow[t]{8}{*}{ NOG } & 0.92 & 0.85 & 1458.9 & 30.93 & 7.37 & $<0.001$ & $b_{0}$ (intercept) & & & 10393.0 & 3160.2 & 3.29 & $<0.01$ \\
\hline & & & & & & & $b_{1}(\mathrm{~N} . \mathrm{HEMI}+\mathrm{dSST})$ & 0.27 & 0.21 & 29.6 & 23.0 & 1.29 & 0.205 \\
\hline & & & & & & & $b_{2}(\mathrm{ALPI})$ & -0.03 & 0.10 & -85.0 & 307.4 & -0.28 & 0.784 \\
\hline & & & & & & & $b_{3}(\mathrm{WP})$ & -0.17 & 0.07 & -2796.7 & 1174.8 & -2.38 & $<0.05$ \\
\hline & & & & & & & $b_{4}(\mathrm{LOD})$ & -0.32 & 0.17 & -1339.7 & 691.1 & -1.94 & 0.060 \\
\hline & & & & & & & $b_{5}(\mathrm{Ap})$ & -0.46 & 0.17 & -454.5 & 166.4 & -2.73 & $<0.05$ \\
\hline & & & & & & & $b_{6}(\mathrm{AO})$ & 0.25 & 0.11 & 3728.3 & 1649.9 & 2.26 & $<0.05$ \\
\hline & & & & & & & $b_{7}(\mathrm{SSI})$ & 0.16 & 0.09 & 10.3 & 5.9 & 1.76 & 0.087 \\
\hline \multirow[t]{7}{*}{ Far East } & 0.93 & 0.86 & 2009.8 & 40.21 & 6.38 & $<0.001$ & $b_{0}$ (intercept) & & & 10285.8 & 2383.3 & 4.32 & $<0.001$ \\
\hline & & & & & & & $b_{1}(\mathrm{~N} . \mathrm{HEMI}+\mathrm{dSST})$ & 0.59 & 0.12 & 94.6 & 19.5 & 4.85 & $<0.001$ \\
\hline & & & & & & & $b_{2}(\mathrm{Ap})$ & -0.44 & 0.12 & -634.6 & 166.6 & -3.81 & $<0.001$ \\
\hline & & & & & & & $b_{3}(\mathrm{PNA})$ & -0.07 & 0.09 & -2087.7 & 2868.5 & -0.73 & 0.471 \\
\hline & & & & & & & $b_{4}(\mathrm{WP})$ & -0.17 & 0.07 & -4144.2 & 1718.6 & -2.41 & $<0.05$ \\
\hline & & & & & & & $b_{5}(\mathrm{AO})$ & 0.15 & 0.09 & 3151.0 & 1908.1 & 1.65 & 0.107 \\
\hline & & & & & & & $b_{6}(\mathrm{SSI})$ & 0.11 & 0.08 & 9.6 & 7.5 & 1.27 & 0.211 \\
\hline
\end{tabular}

See remarks in Table 3. 
Sockeye salmon also show the same pattern of correlation coefficients distribution. The Pearson correlation coefficients for juvenile sockeye in September-November range from 0.4 to 0.7 (Fig. 4). In winter, relationships are much weaker for the NOG than for the BPG. In general, the direct interrelation between chum and sockeye salmon productivity and the temperature is observed in a period of autumnal outmigrations while it has divergent trends in the winter.
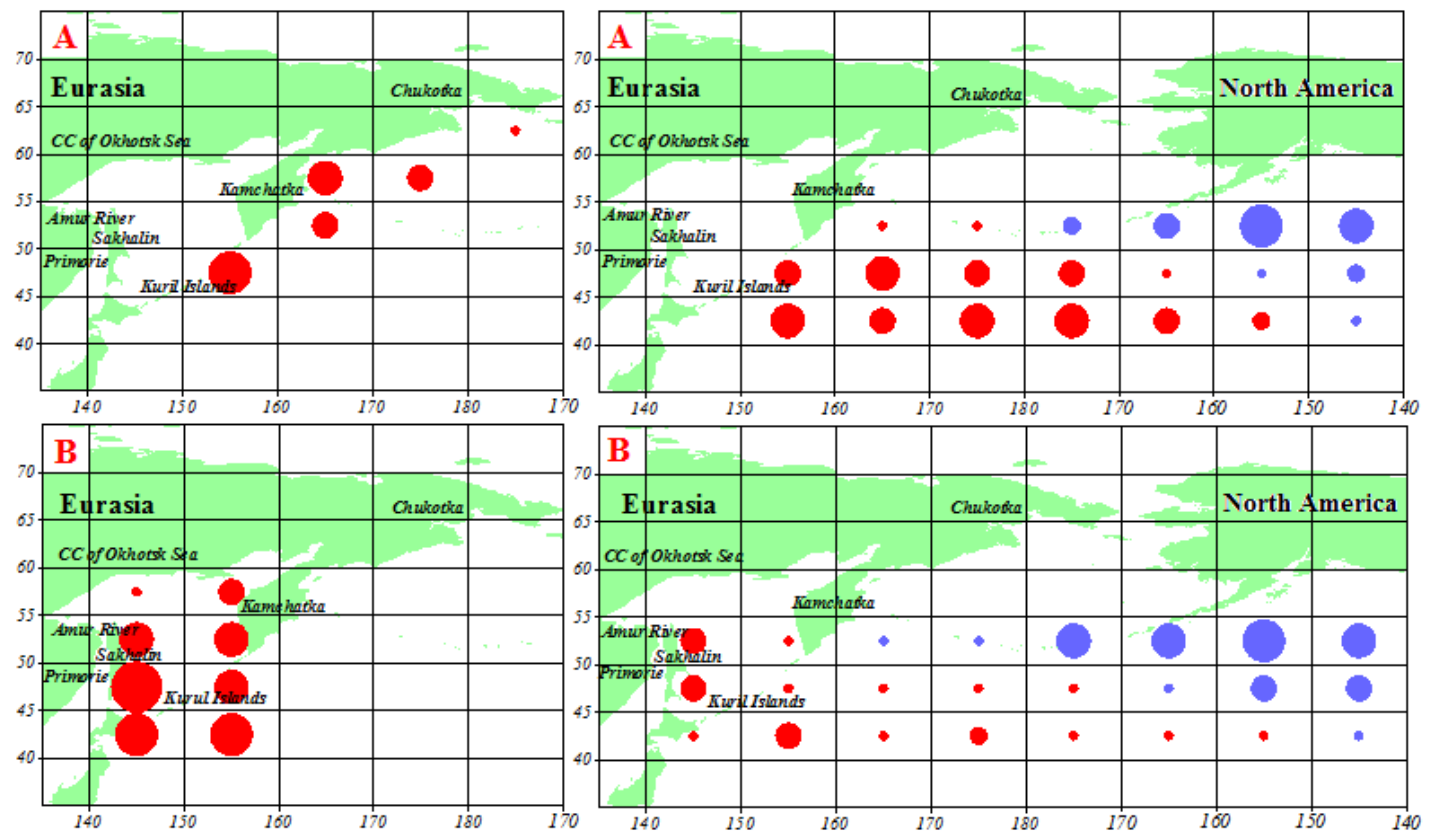

Fig. 4. Distribution of the Pearson's correlation coefficient values between sockeye salmon commercial catches $(1,000$ fish) by regional stock groups and SST anomalies in salmon first marine autumn (left panels) and winter (right panels). Regional stock groups: A-BPG, B-SOG, and C-NOG. Circles size — as on Fig. 2.

In conclusion, the heat budget of the upper water layer and dynamics of solar activity seem to be the major drivers of Pacific salmon productivity in the North Pacific Ocean. For all regional groups and all salmon species under consideration, the N.HEMI+dSST index reflects the strongest effect of positive near-surface air and sea surface temperature anomalies on salmon productivity, especially for chum and sockeye salmon. Negative relationships with the Ap index dynamics reflect a negative effect of enhanced geomagnetic disturbances on salmon stocks' productivity. Distribution of positive and negative correlation coefficients between SST anomalies and chum and sockeye salmon productivity delineates a typical position of two water domains with opposite SST anomalies on the PDO model. This emphasizes the significance of the PDO index as a proxy to forecast the climate change impacts on salmon productivity.

\section{REFERENCES}

Bugaev, A.V., O.B. Tepnin, and K.W. Myers. 2016. Correlation between winter sea surface temperatures in the North Pacific Ocean and continental-scale commercial catches of Pacific salmon, 1983-2013. N. Pac. Anadr. Fish Comm. Bull. 6: 189-205. (Available at http://www.npafc.org)

Levitus, S., J. Antonov, and T. Boyer. 2005. Warming of the world ocean, 1955-2003. Geophys. Res. Lett., 32, L02604. doi: 10.1029/2004GL021592.

Mantua, N.J., S.R. Hare, Y. Zhang, J.M. Wallace, and R.C. Francis. 1997. A Pacific interdecadal climate oscillation with impacts on salmon production. Bull. Amer. Meteor. Soc. 78 (6): 1069-1079.

Radchenko, V.I., O.S. Temnykh, and V.V. Lapko. 2007. Pink Salmon trends in abundance and biological characteristics in the North Pacific. N. Pac. Anadr. Fish Comm. Bull. 4: 7-21. (Available at http://www.npafc.org)

Saito, T., and Y. Miyakoshi. 2018. Current status of chum and pink salmon: what is reducing adult returns in Japan? N. Pac. Anadr. Fish Comm. Tech. Rep. 11. (Available at http://www.npafc.org) 